\title{
Memory, history and digital imagery in contemporary film
}

Robert Burgoyne

Bernardo Bertolucci once said in an interview that the cinema 'is the language through which reality expresses itself . . . to create the language of the cinema, more than with any other form of expression, you have first to put your camera in front of reality, because cinema is made of reality'. ${ }^{1} \mathrm{He}$ also said that every film is a documentary, including fiction films, for every film carries within it an archival record of the period in which it was made, expressed in terms of lighting style, set design, camera work, make up, and even the behavioural gestures and acting techniques of the performers.

Today the idea that the cinema is the language through which reality expresses itself - an idea that has moulded much of film practice and theory from the time of cinema's invention by the Lumière brothers in 1896 - seems to be increasingly under assault. The widespread use of computer generated imagery in film, which allows filmmakers to fuse photographic and digital images - as well as documentary and fictional footage - in the same composited frame, is only one aspect of a rapid and accelerating movement toward replacing celluloid with the infinitely malleable medium of digital imaging, a movement that has made contemporary cinema the emblematic expression, not of the real, but rather of the hyperreal. The rise of digital morphing techniques, for example, along with other forms of electronic manipulation of images in film, and the certain development in the very near future of an interactive digital cinema in which endings can be changed, and troublesome scenes transformed instantaneously according to audience responses, demographics and tastes makes the once intimate connection between cinema and reality remote at best, a distant memory of a century - the century of film, now past - when the ontology of the photographic image could be celebrated by the 
theorist André Bazin as the death mask of reality, as the fingerprint of the real.

Perhaps the greatest champion of the realist vocation of the cinema, Bazin argued that the realism of cinema derived from its existential relation to the physical world: the same rays of light that fell onto the objects of the phenomenal world bounced off those objects and into the lens of the camera, there to be imprinted on the photographic emulsion which preserved that very same light like a fly preserved in amber. For Bazin, the realist aspect of the cinema carried almost religious overtones: he likened film to the Shroud of Turin or Veronica's veil - not just a representation of the real, but rather an actual physical impression. ${ }^{2}$ In the present day, however, the imprimatur of reality that once stamped the cinema has been replaced by the doubt and uncertainty that accompanies computer generated imagery, in which 'mountains, cities, armies [or the Roman Colisseum in the 4th Century A.D.], can be altered or created whole in a digital snap'. ${ }^{3}$ Most importantly, the increasing use of computer generated, artificial visual environments in the movies that we see today appears to threaten not only the certitude and authenticity that we associate with photography, which is often described as a 'visual record', but also the loss of the ethical and moral dimension that Bazin associated with film: its way of insisting on the 'irreducible integrity of people and things beyond ourselves', its way of 'reminding us constantly of our relationship to them'. ${ }^{4}$

This privileged relation to reality that the cinema once enjoyed, and which it appears to have spontaneously sacrificed with its embrace of the hyperreality of electronic image creation, raises particular questions for the way history is represented in film. For films that take history as their subject undertake a dialogue with the real in a way that other films do not. Historical films have real-world reverberations: recent films such as JFK, Braveheart, Glory, The Hurricane and Dances with Wolves have served as a catalyst for the reevaluation of the historical past; they have provoked governments and led to the opening of secret files; they have inspired national consciousness. In a more general sense, film has played an extraordinarily powerful role in shaping our conception of the history of the twentieth century: the films championed by Bazin, for example - the neo-realist films of Rossellini, Visconti and De Sica - have had a deep and lasting effect on our understanding of the effects of World War Two, as have more recent films such as Schindler's List 
and other films dealing with the Holocaust. The powerful effect of films that deal with war, suffering and injustice is intimately related to the way they connect us to their physical and social environments, to the way they connect us to the world, to history.

The ferocious controversies that surround films such as JFK and Forrest Gump appear to me to stem not only from the interpretations they offer of controversial historical events, but also, pointedly, from their departure from the conventions of photo-realism through their use of computer enhanced and computer generated images, by their seamless splicing together of fictional scenes and archival footage, and by their use of documentary footage to re-enact events from a fictional or speculative perspective, blurring the boundary between actuality and fiction. In these films, the status of the 'document' which, as Paul Ricouer reminds us, is the indelible dividing line between history and fiction - is placed in doubt. ${ }^{5}$ We can no longer be sure that the documentary images of John F. Kennedy, George Wallace, John Lennon, Lyndon Baines Johnson and other historical figures that appear in Forrest Gump and JFK are the authentic traces of the past; the archival image can no longer be assumed to be an authentic record of past events. As Thomas Elsaesser writes, 'Future generations, looking at the history of the 20th century, will never be able to tell fact from fiction, having the media as material evidence. But then, will this distinction still matter to them?'

In Elsaesser's view, history itself, partly because of the rise of electronic media, has suffered a serious loss of prestige:

History, when it is not just what's past, but what's being passed on, seems to have entered a conceptual twilight zone, not least because it has become a past that cinema and television can 'master' for us by digitally remastering archival material. While memory, especially when contrasted with history, has gained in value as a subject of public interest and interpretation, history has become the very signifier of the inauthentic ... the false and the falsifiable ... merely designating what is left when the site of memory has been vacated by the living. With the audio-visual media effortlessly re-presenting that site, however, the line where memory passes into history has become uncertain.

In this chapter, I would like to explore some of the implications of computer generated imagery for the cinematic representation of the past. In particular, I will focus on the most contested and controversial area of contemporary fiction cinema's representation of the past - the use of documentary images as a mode of imaginative 
reconstruction or re-enactment. The shift from documentary images being understood as the trace of the past, as something left behind by a past event, to something available for imaginative and poetic reconstruction through computer alteration would seem to present a particular challenge to historical film's claim to capture a certain truth about the past. For although the representation of history in film is a notoriously vexed subject, typically involving controversies over authenticity and accuracy versus the interpretive requirements of narrative form, the more narrow case of the alteration or embellishment of documentary images for the purposes of dramatic storytelling highlights some new questions. The unprecedented conjunction of archival images and computer generated imagery in contemporary films such as Forrest Gump would seem, for example, to directly contradict what Ricouer calls the 'primacy of the referential intention' in historical reconstruction. With its increasing use of morphing techniques and computer generated visual environments, the cinema would seem to be a medium that now refuses history in the traditional sense of origins, authenticity and documentation.

And yet, contrary to expectation, film in the present day appears to have strengthened its cultural claims on the past. The cinematic rewriting of history has, in the present cultural moment, accrued an extraordinary degree of social power and influence. Film appears to have acquired, more than ever, the mantle of meaningfulness and authenticity with relation to the past - not necessarily of accuracy or fidelity to the record, but of meaningfulness, understood in terms of emotional and affective truth. Cinema, in effect, seems to evoke the emotional certitude we associate with memory for, like memory, film is now, to a greater extent than before, associated with the body; it engages the viewer at the somatic level, immersing the spectator in experiences and impressions that, like memories, seem to be burned in.

I will begin by summarising an important argument that has been made by Alison Landsberg, who has coined the striking term 'prosthetic memory' to describe the way mass cultural technologies of memory, such as film, enable individuals to experience, as if they were memories, events through which they themselves did not live. She cites the growing popularity of experiential museums, such as the Holocaust Museum in Washington DC, of historical re-enactments, including the relatively recent D-Day celebrations, and of historical films such as Schindler's List as evidence of a widespread 
cultural desire to re-experience the past in a sensuous form, and stresses the power of what she calls experiential mass cultural forms to make historical or political events meaningful in a personal, local way. The new modes of experience, sensation and history that are made available in American mass culture, she writes, 'have profoundly altered the individual's relationship to both their own memories and to the archive of collective cultural memories'. ${ }^{8}$ Defining the concept of prosthetic memory as 'memories that circulate publicly, that are not organically based, but that are nonetheless experienced with one's own body - by means of a wide range of cultural technologies', Landsberg argues that prosthetic memories, especially those afforded by the cinema, 'become part of one's personal archive of experience'. ${ }^{10}$ The artificial but real experiences afforded by the cinema 'might actually install in individuals "symptoms" through which they didn't actually live, but to which they subsequently have a kind of experiential relationship'. ${ }^{11}$ Although the production and dissemination of memories that are defined not by organic, individual experience but by simulation and re-enactment are potentially dangerous, posing the threat of alienation and revisionism, prosthetic memories also enable a sensuous engagement with past lives and past experiences that, Landsberg argues, can serve as 'the basis for mediated collective identification'. ${ }^{12}$

These arguments appear to have a particular salience for understanding the popularity and the larger cultural significance of films such as Forrest Gump, JFK, Glory, The Hurricane and Saving Private Ryan. In many ways, these films seem to literalise the concept of prosthetic memory. They explicitly take on the role of offering an experiential relation to history, inserting their main characters and, by extension, their viewers, into what appears to be a physical, literal relationship to actual historical figures and events: in Forrest Gump, for example, the film splices the character of Gump into fictionalised interactions with historical figures captured in archival film images Gump is seen shaking hands with JFK and Richard Nixon, standing on the University of Alabama steps with George Wallace and conversing with John Lennon. And in the case of Steven Spielberg's Saving Private Ryan, the film creates a visceral, sensesurround experience of the D-Day invasion with excruciatingly realistic effects. What Landsberg calls the 'widespread desire on the part of Americans to experience and to live history', the desire to experience history in a 'personal, bodily way', ${ }^{13}$ is exemplified in these films. 
The cinema is thus revealed, in the most emphatic way, to be an instrument that allows individuals to 'experience a bodily, mimetic encounter with a collective past they never actually led', experiences that foreground the multiple and complicated relations between individual and collective memory and history in the age of media culture.

Memory, in the traditional sense, describes an individual relation to the past, a bodily, physical relation to an actual experience that is significant enough to inform and colour the subjectivity of the rememberer. History, on the other hand, is traditionally conceived as impersonal, the realm of public events that have occurred outside the archive of personal experience. But in contemporary media culture, the most significant 'historical' events are often transformed into spectatorial 'experiences' that shape and inform the subjectivity of the individual viewer; with the media continually and effortlessly re-presenting the past, history, once thought of as an impersonal phenomenon, has been replaced by 'experiential' collective memory. Electronic or audio-visual 'lieux de memoire' (sites of memory) have created a kind of second order memory system that is fast becoming a second order reality. As Elsaesser writes,

we may be deceiving ourselves [if we] contrast too sharply authentic memory with inauthentic (media-) history. A new authenticity may be in the making... When we ask: 'Do you remember the day Kennedy was shot?', do we not actually mean 'Do you remember the day you watched Kennedy being shot all day on the television?' . . . Or after the Challenger disaster, when the space shuttle seemed to explode into a starburst of white smoke over and over again, until we could no longer tell the television screen from our retinas? ${ }^{14}$

Elsaesser, however, seems wary of the experiential effects of mass media, arguing that the seemingly physical, experiential relation to the historical event and the historical past that mass technology affords may inhibit the narrative closure that storytelling and narrative history allow. Rather than generating historical amnesia, as is so often claimed, film and media may generate its opposite, an inability to stop obsessing about an event: 'No longer is storytelling the culture's meaning-making response; an activity closer to therapeutic practice has taken over, with acts of re-telling, remembering, and repeating all pointing in the direction of obsession, fantasy, trauma. ${ }^{15}$ In this view, the mass media create cultural memories that resist the kind of narrative closure associated with storytelling, with 
narrative history. He asks what obscure urge is satisfied by the compulsion to repeat that seems to drive the mass media in its continuous presenting and re-presenting of historical trauma, a question that has gained in importance and urgency after 11 September 2001. Hayden White has described twentieth-century historical events as 'modernist'; the lack of closure, the fragmentation and dissociation of one event from another, the inability of historians and the public at large to 'master' and contain events in narrative form, may be a consequence, he writes, of the unprecedented scale and compound contexts of 'modernist' historical events, such as the Holocaust, the Vietnam War, the assassination of JFK, and now the attack of 11 September. ${ }^{16}$ Taking White's hypothesis one step further, Elsaesser suggests that the lack of closure in modernist historical events may be a property of the mass media itself and its take on history, which tends to create in the spectator symptoms of obsession and trauma. In the optimistic account of prosthetic memory provided by Landsberg, the somatic powers of mass technology to produce something like symptoms in the spectator create the potential for empathic identification, for new collective frameworks, for public spheres based on memory. In Elsaesser's less sanguine perspective, the burning in of memories via the media - burned in to the point that they create symptoms in the spectator - speak not to empathy and new social alliances but rather to cultural obsession, fantasy, and trauma.

Elsaesser's and Landsberg's suggestion that a new kind of authenticity may be in the making, one which includes media events as a form of individual and collective experience, is a striking insight. But although this idea is provocative and persuasive enough as regards memory and the media, it falls short of considering the wild card effect that digital imaging has on this conception of the authenticity of mediated experience. For, as Elsaesser says elsewhere, there is a particular kind of postmodern hubris at work in contemporary media culture, expressed most powerfully in the widespread faith that film and video can 'redeem the past, rescue the real, and even rescue that which was never real'. ${ }^{17}$ Here, I would like to offer a small counterexample of the cinema's power to inform subjectivity and 'rescue that which was never real'. In a recent Hollywood film entitled Wag the Dog, a Hollywood producer in league with the President's closest advisors concocts a fake war with Albania to distract the country from a scandal involving the President and a young girl. The key element in this fake war is phony news footage of the 
rescue of a young Albanian woman fleeing the smouldering ruins of her village. The news footage that the Hollywood producer concocts for this disinformation campaign, of course, is computer generated, with every detail, including the amount of smoke, the placement of the burning buildings, the small bridge over which she runs and the colour of the cat she rescues from the ruins, created and composited together by computer. Through elaborate devices such as this, the nation comes to believe in the reality of the fake war, which comes complete with a fake hero. Here the cinema clearly 'redeems the past, rescues the real, and even rescues that which was never real'. Wag The Dog serves as a dazzling example of the potential of computer generated imagery to create utterly realistic 'events'; it also serves as a strong cautionary tale concerning the faith we place in the cinema as a form of integral realism, as 'a recreation of the world in its own image, an image unburdened by the freedom of interpretation of the artist or the irreversibility of time'. ${ }^{18}$

The realist style championed by Bazin carried a particular message about history and its relation to individual existence: the privileged meaning of the photo-realist style is that it keys the spectator in to the passing of time, to the saturation of space with meaning, and to the organic link between the actor and the setting in which the action occurs. In favouring the long take over montage, for example, Bazin argued that the long take - the unbroken shot of extended duration - accentuated the meaning and value of temporality on the screen; temporality in the photo-realist style is directly related to the spectator's own 'embodied perception of lived time and transformation'.$^{19}$ In the long take, and for that matter in the photo-realist style in general, human emergence is accomplished in real historical time, laboriously, with difficulty, and irreversibly. With the ascendance of computer generated imagery in film, however, with its ease of transformation and quick change potential - a potential figured most prominently in the use of computer warping and morphing there is a radical transformation of the spatial and temporal coordinates of the cinema and its relation to human experience, a transformation, as Vivian Sobchack says, of the 'spatial and temporal grounding of the photo-realist cinema that up until now has been indexically related to human physical existence as it is daily experienced in space and time'. ${ }^{20}$

With the technology of digital compositing and morphing, as exemplified in the digital images of Forrest Gump, two or more 
temporally distinct moments are composited together. In Gump older $16 \mathrm{~mm}$ film images of John F. Kennedy are composited together with new $35 \mathrm{~mm}$ footage of Tom Hanks as Gump, and the differences between the two are blended together through digital morphing. ${ }^{21}$ Gump now seamlessly appears to be interacting with Kennedy, whose words to Gump are created from a sampled composite of Kennedy's recorded speech, and whose mouth movements are synchronised to the words by way of computer morphing. This sequence of Kennedy, culled from the archives, thus no longer originates from a fixed moment in history, no longer carries, as Bertolucci would say, the archival trace of the moment of its shooting: it rather carries a double temporality, conveying its separate origins - Kennedy from the past of 1962, Hanks as Gump from the past of 1994 - as well as the resulting morphed single present.

There seems to be little question that computer effects are 'subtly changing the nature of reality as experienced through moving images'. ${ }^{22}$ Whereas cinema came into being as a way of recording the real and preserving time, computer generated imagery creates its own time and duration, its own synthetic spaces, and its own interface between the actor and the background setting in which the action seems to occur. These developments move cinema away from the real and away from history in the traditional sense of origins, documentation, and lived duration. However, despite the loss many of us may feel over cinema's sacrifice of this essential recording and preserving function, it is nevertheless the case that computer generated imagery is a key marker of our time; computer morphing, in particular, has been called the contemporary period's most important trope. ${ }^{23}$ In a period defined by the blurring of boundaries of race, gender, and nation, by the collapse of the clear-cut distinction between the natural and manufactured worlds, by the merging of biology and technology and by the uncertainty surrounding the past, which is now available to be replayed, endlessly, with digital enhancements, computer generated imagery can be seen as a privileged 'visual demonstration of the boundary fluctuations that humans and their worlds are experiencing', a privileged form of the cultural imaginary in the early years of the twenty-first century. ${ }^{24}$

The question that I still consider at issue, however, is whether this new trope, this new culturally dominant technique of imaging, can be placed in the service of historical representation and understanding. Here I will discuss three different films which I feel illustrate both the 
negative and the positive potential for the new kind of interweaving of fiction and history that computer generated imagery allows.

One of the most striking uses of digital compositing and morphing in film is found in Forrest Gump, which at certain points digitally rewrites some of the most sensitive scenes of the American past. In the first few images of the film, Tom Hanks's face is composited and morphed into an image from D. W. Griffith's The Birth of A Nation. The film superimposes Hanks' face onto that of a Ku Klux Klansman from the film. Gump (played by Hanks) then narrates how he was named after the 'famous Civil War general Nathan Bedford Forrest', who 'started up a club called the Ku Klux Klan'. As we watch scenes from The Birth of a Nation, Gump talks about how the club 'liked to dress up in white sheets, and act like a bunch of ghosts or spooks or something; they even put sheets on their horses.' Scenes from Griffith's famous film, with Tom Hanks seeming to ride at the head of the Klan, unfold before our eyes. As the film progresses, the history of racial conflict that Forrest Gump evokes in its opening scenes intersects with Gump's own experiences, as his image is digitally inserted into newsreel footage of the integration of the University of Alabama. As two black students are seen walking into the classroom building over the protests of Governor George Wallace and under the protection of Federal troops, the figure of Forrest Gump appears, digitally grafted into the newsreel footage, glancing into the camera. Then, in a staged sequence composited into the actual newsreel footage, Gump picks up a book one of the black students had dropped and hands it to her. He waves to the hostile crowd, and then follows her into the schoolhouse.

In effect, Forrest Gump is now inscribed into the historical archive as a figure that ameliorates the history of racial intolerance associated with his namesake, the Ku Klux Klan leader Nathan Bedford Forrest. Digitally inserted into two famous scenes, one from a fictional source - The Birth of a Nation - the other the documentary newsreel footage of George Wallace - the figure of Forrest Gump serves the exemplary function of 'redeeming the past, rescuing the real, and even rescuing that which was never real'. In the confrontation on the University of Alabama steps, for example, George Wallace's inflammatory statements about the Federal Government, and his vocal defiance of the court's desegregation order, are omitted; instead, Gump's inability to comprehend what the confrontation is about becomes the centre of the scene. Gump's insertion into 
the historical archive suggests a kind of reconciliation, a healing acceptance - one prompted, however, not by an understanding of the history of racial oppression but rather by a lack of understanding, by an absence of historical knowledge.

Later, other equally famous documentary images and moments in history are reconstituted for our gaze: Gump shakes hands and converses with John F. Kennedy, Lyndon Baines Johnson and Richard Nixon, he appears on a talk show with John Lennon and he meets Robert F. Kennedy. In each of these encounters, the meaning of the past is decisively changed. In the scene with Lennon, for example, Lennon is shown finding inspiration for the song 'Imagine' from Gump in a way that reverses the meaning of the song itself. Archival footage of Lennon's appearance on the Dick Cavett Show from the 1960s is composited together with Gump talking about his recent visit to China, and expressing amazement about the atheism, collective ownership and antimaterialism that he found there. Lennon appears to respond to Gump's descriptions of life in China with the word 'Imagine!', which he repeats after all of Gump's incredulous descriptions. As with the George Wallace and John F. Kennedy sequences, Lennon's recorded words are culled from the archive, and his mouth movements morphed so that they seem to form the word 'imagine'. In this context, Lennon's morphed response seems to imply that Gump's descriptions of the alien mode of life in China became the genesis of the famous song. Thus, a song that protests against the power of materialism, nationalism, and religion is transformed in Forrest Gump into a celebration of American values: the revolutionary message of the song is turned into a statement that seems to endorse the American way.

History and reality are here reprocessed to the point that 'old reality, unmorphed reality . . . begins to look fake and unreal'. Forrest Gump the character, as one commentator says, 'looks more real than any US president - or historical event we have seen'. ${ }^{25}$ In Forrest Gump, as Joseba Gabilondo writes, 'history is no longer a reality fixed by the truth of mimetic representation ... history is no longer real, but hyperreal and open to change. Any subject can access history and rewrite it from its own position ... History can be accessed and then morphed, reproduced, and changed in such a way that one's own position need no longer be marginal or peripheral'. ${ }^{26}$ By morphing the character Forrest Gump into the archive of actual history, 'into the record', as it were, Forrest Gump, the film, 
rewrites the social and historical past in a way that dovetailed with conservative and reactionary political movements in the mid-1990s, many of which used the film as a rallying cry for fundraising and for political campaigns.

In the two other films I will discuss here, however, I feel that digital morphing and computer enhanced imagery does in fact give us a deep understanding of temporal process, of change over time, and of the way the past itself changes under the pressure of new perspectives.

A powerful example of the positive potential of this new trope can be found in a short film by Daniel Reeves, entitled Obsessive Becoming. By digitally morphing and warping generations of documentary family photographs and home movies, Reeves shows a child changing into an adult, shows the features of the filmmaker's nineteenthcentury ancestors morphing into the features of later generations, and shows the elderly seeming to transform again into children, demonstrating in a palpable and astonishing way the physical connection across and within generations, 'the persistence over time of a bloodline and a history'. One critic writes about the film: 'Along with keen hand tintings and other painterly treatments, the hi-tech effect of morphing finally becomes not so much graphical pizzazz as a visual recognition of our seamless linkage to the past', ${ }^{27}$ 'a timeless litany of both family dispersion and eternal return'. ${ }^{28}$ Here, the temporality of becoming, of one generation flowing into another, of faces and features changing and then reappearing later, in a subsequent generation, in a slightly different key, exemplifies the timelessness as well as the historical nature of human existence. The singular details attached to the individual lives portrayed in this film and the weight of their specific histories and specific events is encapsulated within an overall movement of time flowing onward. The film ultimately gives 'human (not computergraphic) emphasis and value to the lives and times [the filmmaker] weaves together' ${ }^{29}$

Another film that I feel points the way toward a productive breakdown of boundary distinctions in the representation of the past is Oliver Stone's JFK. Although JFK doesn't use the type of computer generated imagery - the compositing, warping, and morphing - that Forrest Gump and Obsessive Becoming employ, it does approximate the effect of compositing and morphing by splicing together documentary footage and staged sequences with great rapidity. It also uses pseudo-documentary sequences - staged sequences made to 
look grainy, badly lit, and scratched so as to resemble $16 \mathrm{~mm}$ documentary footage - and places existing documentary footage into new contexts. Thus the film, like Forrest Gump, makes it hard to distinguish fact from speculative fiction: as Elsaesser says, a future generation would hardly be able to tell the archival documentary images from the staged sequences in JFK. Here the line between realistic and imaginative discourses is perpetually crossed and recrossed.

Crucially, however, the famous documentary film made by Abraham Zapruder which records the assassination of Kennedy, and which Stone uses to immensely powerful effect in the trial scene in the film, is not computer enhanced or altered by digital effects in any way: it is, Stone asserts, shown exactly as it is was shot; although the images are magnified, blown up from the original $8 \mathrm{~mm}$ to $35 \mathrm{~mm}$, and cropped so that the focus is more and more closely drawn to the President's wounding as the sequence is repeated in the trial scene of $J F K$. The Zapruder film as used in JFK is essentially unaltered - not digitally manipulated or subjected to computer enhancement.

Certain scenes do combine documentary, archival images with staged footage in a nearly seamless way, however, and these scenes do produce something like a new accentuation, a subtle nuancing of the historical archive. For example, the scene of Lee Harvey Oswald's shooting in the basement of the Dallas Sheriff's office is shown initially in blurry, black and white television style footage; these images are the actual archival footage of the event from the television news coverage of that day. Then, Stone introduces a staged sequence of shots, a series of close-ups, reverse angles and reaction shots that are photographed in a more vivid black and white style. Here, it seems as if Oswald and Jack Ruby look at one another before the shooting, suggesting that perhaps they know each other, that perhaps they recognise each other. The psychological dimension that is introduced here, as Oswald and Ruby are given the kind of close-up portraiture and eyeline connection that implies subjectivity, that implies motivation, orients the historical event of Oswald's murder in the direction of conspiracy: Stone imaginatively 'enters' the scene of Oswald's murder, rethinks it, presents it from a psychological perspective and defamiliarises images long established as part of the historical archive. Then, at the climactic moment of the shooting, he cuts back to the actual archival footage, showing the authentic clip of Oswald's murder, which now has a subtle but distinct new message attached to it, a message concerning the strong 
possibility of a conspiracy, of a connection between Oswald and Ruby that has turned fatal for Oswald.

The cinematic rewriting of the historical past is here pushed to the level of the historical documents themselves. As in Forrest Gump, the audio-visual archive of American history in the twentieth century is quoted, reimagined, and reinterpreted through the use of cinematic techniques that make it difficult to distinguish between archival footage and dramatic interpretation. Stone has said that 'the style of my films is ambivalent and shifting. I make people aware that they are watching a movie. I make them aware that reality itself is in question ... the movie is not only about a conspiracy to kill President Kennedy, but also about the way we look at our recent history. $[J F K]$ calls attention to itself as a means of looking at history - shifting styles, such as the use of black and white and color, and viewing people from offbeat angles'. ${ }^{30}$

Although Stone is careful not to alter or tamper with the documentary images themselves, his imaginative quoting and re-presenting of the audio-visual documents by rapidly splicing in staged footage that seems to flesh out, or elaborate on the material in the archive produces an effect that is similar to director Robert Zemeckis' morphing and compositing techniques in Forrest Gump. In both cases, the meaning of the documents is altered: in the case of Forrest Gump, by an actual transformation, placing Forrest in photographic scenes with George Wallace, John F. Kennedy, and others in such a way that Kennedy and Wallace, for example, are made to appear to interact with Forrest. In the case of $J F K$, the audio-visual documents are in effect reaccentuated, remotivated, reenacted, by Stone's inventive montage technique, one that brings together factual, fictional, and speculative imagery.

As Robert Rosenstone writes, it is possible that such history on the screen is the history of the future. Perhaps in a visual culture, the truth of the individual fact is less important than the overall truth of the metaphors we create to help us understand the past... The visual media may represent a major shift in consciousness about how we think about our past'.

I would like now, in closing, to return to a point made by Elsaesser which I quoted earlier in this paper, and which I would like now to consider in a different light. That quote is the following: 'Future generations, looking at the history of the 20th century, will never be able to tell fact from fiction, having the media as material evidence. 
But then, will this distinction still matter to them?' I expect most readers will be vaguely troubled by this quote, troubled by the idea that fact and fiction as presented in the media would be indistinguishable to a future generation, but perhaps even more troubled by what seems to be the throwaway line, 'But then will this distinction still matter to them?' But let us consider this point again. Could it be that in the history of the future this distinction will not be so crucial? As Rosenstone writes, 'Fact has not always been the primary tool for telling the past. The truth of facts was never very important to griots in Africa or to history makers in other oral cultures. Perhaps Oliver Stone is a kind of griot for a new visual age. ${ }^{32}$

To consider the documentary images of the history of the twentieth century, what most people consider to be the audio-visual record of the recent past, as simply part of the image bank, material available for poetic or metaphoric use, challenges our sense of the sacrosanct nature of the document which, as Ricouer points out, 'marks a dividing line between history and fiction'. ${ }^{33}$ But in fact, this form of visual history, one that uses documentary images in the service of storytelling that freely mixes fictional, factual and speculative discourses, gives us a history of the future that is in some ways very like the mythic histories of the past. Perhaps, for future generations, the distinction between fact and fiction as presented in the media will no longer matter because a whole new genre of visual history, or history as vision, will have emerged with its own rules, its own regimes of credibility, and its own sort of truth. For them, and perhaps even for us, documentary images may no longer signify the facticity of past events, per se, but rather convey the sense that they are a representation of the past, a representation that may be employed for the purpose of metaphor, irony, analogy or argument, and that may be used in such a way that a certain poetic truth may emerge in the telling. Interestingly, Bazin, the great theorist of realism in the cinema, provides a way of thinking about hyperrealism in film when he writes: 'Every new development added to the cinema must, paradoxically, take it nearer and nearer to its origins. ${ }^{34}$ Although Bazin probably meant that cinema would eventually arrive at a perfect replication of the real, computer generated imagery in fact pushes the cinema's origins back beyond the nineteenth- and twentieth-century dream of the mechanical or electronic reproduction of reality, all the way to premodernity, to medieval or mythic times when the line between fantasy, fact and speculation was not yet clearly drawn. ${ }^{3.5}$ 


\section{Notes}

1 Geoffrey Nowell-Smith and Ilona Halberstadt, 'Interview with Bernardo Bertolucci', in Fabien S. Gerard, T. Jefferson Kline and Bruce Sklarew (eds), Bernardo Bertolucci: Interviews (Jackson: University Press of Mississippi, 2000), p. 248.

2 See André Bazin, What Is Cinema? vols 1-2, trans. Hugh Gray (Berkeley: University of California Press, 1967-71).

3 Godfrey Cheshire, 'The Death of Film', www.artswire.org.

4 Ibid.

5 Paul Ricouer, The Reality of the Historical Past (Milwaukee: Marquette University Press, 1984), p. 1.

6 Thomas Elsaesser, 'One Train May Be Hiding Another: Private History, Memory, and National Identity', Screening The Past (May 1999), 2.

7 Thomas Elsaesser, 'Subject Positions, Speaking Positions: From Holocaust, Our Hitler, and Heimat to Shoah and Schindler's List', in Vivian Sobchack (ed.) The Persistence of History (New York: Routledge, 1996), p. 145.

8 See Alison Landsberg, 'Prosthetic Memory: The Logic and Politics of Memory in Modern American Culture' (PhD dissertation, University of Chicago, 1996), p. 13.

9 See Alison Landsberg, 'America, the Holocaust, and the Mass Culture of Memory: Toward a Radical Politics of Empathy', New German Critique 71 (Summer 1997), 63-86, p. 66.

10 Landsberg, 'Prosthetic Memory: The Logic and Politics of Memory in Modern American Culture', p. 24.

11 Landsberg, 'Prosthetic Memory: The Logic and Politics of Memory in Modern American Culture', p. 23.

12 Landsberg, 'Prosthetic Memory: The Logic and Politics of Memory in Modern American Culture', p. 4. See also Alison Landsberg, 'Prosthetic Memory: Total Recall and Blade Runner', in Mike Featherstone and Roger Burrows (eds), Cyberspace/Cyberbodies/Cyberpunk: Cultures of Technological Embodiment (London: Sage, 1995), pp. 175-89 and 'America, the Holocaust, and the Mass Culture of Memory'.

13 Landsberg, 'America, the Holocaust, and the Mass Culture of Memory', p. 75 .

14 Elsaesser, 'One Train May Be Hiding Another', p. 6.

15 Elsaesser, 'Subject Positions, Speaking Positions', p. 146.

16 Hayden White, 'The Fact of Modernism: The Fading of the Historical Event,' in Vivian Sobchack (ed.), The Persistence of History (New York: Routledge, 1996), pp. 17-38.

17 Elsaesser, 'Subject Positions, Speaking Positions', p. 166.

18 Joseba Gabilondo, 'Morphing Saint Sebastian: Masochism and Masculinity in Forrest Gump', in Vivian Sobchack (ed.), Meta-Morphing 
(Minneapolis: University of Minnesota Press, 2000), p. 185.

19 Vivian Sobchack, "At the Still Point of the Turning World" MetaMorphing and Meta-Stasis', in Meta-Morphing, p. 134.

20 Sobchack, "'At the Still Point of the Turning World", p. 138.

21 See Gabilondo, 'Morphing Saint Sebastian', p. 186. See Also Stephen Prince, 'True Lies: Perceptual Realism, Digital Images, and Film Theory, Film Quarterly 49: 3 (Spring 1996), 30.

22 Woody Hochswender, 'When Seeing Cannot Be Believing', New York Times (23 June 1992), 1.

23 Louise Krasniewicz, 'Magical Transformations: Morphing and Metamorphosis in Two Cultures', in Sobchack (ed.), Meta-Morphing, p. 54.

24 Krasniewicz, 'Magical Transformations, p. 55.

25 Gabilondo, 'Morphing Saint Sebastian', p. 201.

26 Ibid.

27 Steven Seid, 'Obsessive Becoming: The Video Poetics of Daniel Reeves in Works by Daniel Reeves', www.mediopolis.de/transmedia/english, 13 May 1999.

28 Sobchack, “'At the Still Point of the Turning World”, p. 143.

29 Ibid.

30 Oliver Stone, 'Stone on Stone's Image (As Presented by Some Historians)', in Robert Brent Toplin (ed.), Oliver Stone's USA (Lawrence: University Press of Kansas, 2000), p. 53.

31 Robert Rosenstone, 'Oliver Stone as Historian', in Toplin (ed.), Oliver Stone's USA, p. 39.

32 Rosenstone, 'Oliver Stone as Historian', pp. 38-9.

33 Ricouer, The Reality of the Historical Past, p. 1.

34 André Bazin, 'The Myth of Total Cinema', in What Is Cinema?, p. 21.

35 Gabilondo, 'Morphing Saint Sebastian', p. 186. 